\title{
ROBERTO VENEGEROLES
}

\section{SAMIRA MURAD}

\section{RENATO VICENTE}

\section{A tela do}

\section{conhecimento:}

\section{modo de usar}

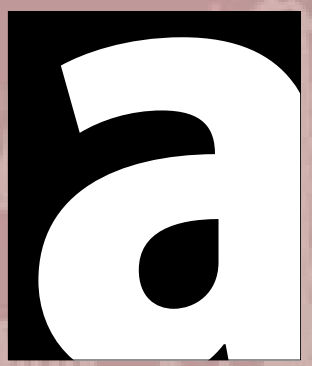

disponibilização quase acidental de novas tecnologias leva a uma cadeia de conseqüências que, não raramente, culmina em uma reinterpretação completa de nossa visão de mundo. Assim ocorreu com o relógio mecânico, com as máquinas a vapor, com a energia elétrica, o computador e agora com a world wide web ( $w w w)$. Dessa forma, sem exaurir a questão, podemos dizer que, assim como o relógio nos fez pensar no mundo como preciso, redutível e previsível, o computador nos fez pensar na possibilidade de simular o mundo (ou talvez, no mundo como uma simulação). 
Em um conto datado de 1941, Jorge Luis Borges (2000, p.94) imaginou uma biblioteca em forma de esfera cuja circunferência seria inacessível. Seria composta de um número indefinido, possivelmente infinito, de galerias hexagonais. Existiria $a b$ aeterno e nela não haveria dois livros idênticos. Seria ilimitada e periódica. Em alguma prateleira de algum hexágono existiria um livro que seria a chave e o compêndio de todos os demais. A biblioteca seria total, teria todos os livros em qualquer idioma, a versão de cada livro em todas as línguas e as interpelações de cada livro em todos os demais.

A www nos fornece possibilidades de publicação e troca de informação de forma imediata e global.Vivemos em um mundo crescentemente interconectado com uma biblioteca borgiana a se realizar por trás

ROBERTO

VENEGEROLES

é professor do Centro de Matemática,

Computação e Cognição da Universidade Federal do $A B C$.

\section{SAMIRA MURAD}

é doutoranda no Departamento de Letras Modernas da FFLCH-USP.

\section{RENATO VICENTE}

é pesquisador do

Grupo de Física do Processamento de Informação e Economia (Grife) da Escola de Artes, Ciências e Humanidades (USP-Leste). de nossas telas de computador. A forma como resolvemos os problemas de produção, acesso e leitura da informação contida nessa biblioteca tem impacto na maneira como vemos o mundo. Agora muitos de nós somos ao mesmo tempo produtores e leitores de volumes eletrônicos, buscamos por novas tecnologias que nos permitam achar caminhos para informação relevante e nos confrontamos com a necessidade de reaprender a ler e a contar histórias.

Neste artigo procuramos traçar um panorama de relações entre as novas tecnologias de informação, em particular de produção de textos digitais, a forma como textos são publicados e lidos, e o modo como se buscam conteúdos. 


\section{A PRODUÇÃO ABERTA}

Na Antiguidade, os manuscritos, feitos à base de papiros ou pergaminhos, eram produzidos volume por volume em um trabalho artesanal acessível somente às bibliotecas e coleções particulares de reis e outras autoridades. A popularização de manuscritos aconteceria somente a partir da difusão do papel no século XIV e do surgimento de tipografias no século XV. Livros populares já circulavam pela Europa em pleno século XVI. Nessa época, a literatura de cordel ganhava espaço na Espanha e em Portugal. Os chapbooks, pequenos livros comercializados por vendedores ambulantes, começavam a se tornar populares na Inglaterra, enquanto acervos móveis já circulavam com alguma regularidade também pela França (Manguel, 1997; Chartier, 1994).

Os avanços tecnológicos acumulados no decorrer dos séculos contribuíram de forma significativa para o processo de universalização do acesso à informação, em particular em sua forma escrita. $\mathrm{O}$ advento da internet no fim do século XX não somente reafirma essa tendência como também nos transporta, alguns passos adiante, a um cenário completamente novo e transformador: a possibilidade de que todos sejam, ao mesmo tempo, emissores e receptores de informação.

Dentre a miríade de veículos não convencionais de informação que surgiram a partir dessa nova tecnologia, provavelmente o mais icônico e polêmico de todos seja a Wikipedia, uma enciclopédia multilíngüe criada em 2001. A Wikipedia tem conteúdo aberto e colaborativo, ou seja, é escrita voluntariamente por inúmeras pessoas de diversas regiões do mundo. Qualquer artigo dessa enciclopédia virtual pode ser transcrito, modificado e ampliado, desde que preservados os direitos de cópia e modificações.

Os críticos da informação eletrônica de conteúdo aberto, tal como a Wikipedia, alegam que informações veiculadas nesses domínios têm menores chances de estar corretas do que aquelas publicadas em livros impressos de editoras respeitadas. Uma comparação efetuada (Giles, 2005) entre a Wikipedia e a Encyclopedia Britannica, no entanto, produziu resultados surpreendentes ao mostrar evidência de que a qualidade da enciclopédia aberta seria semelhante à da enciclopédia tradicional. A qualidade do estudo, publicado na revista Nature, foi, contudo, severamente contestada pela Encyclopedia Britannica ${ }^{1}$. Segundo Chartier $^{2}$, de forma geral existe um sistema de referências que hierarquiza as possibilidades de acerto no mundo impresso que não existe no mundo digital aberto. Esse sistema funcionaria como um filtro de proteção, ainda que imperfeito, às ameaças de plágios e informações falsas.

A possibilidade de uma dinâmica autoorganizada para produção de informação de alta qualidade continua um problema em aberto, visto que grande sucesso tem sido atingido desenvolvendo-se software dessa maneira. $O$ processo de produção segue uma dinâmica evolucionária baseada na reprodução, recombinação e seleção de idéias em ambos os casos. Talvez uma diferença crucial entre a produção de textos e a produção de software resida na definição e, conseqüentemente, na mensuração bem menos problemática de qualidade do produto final no segundo caso.

Uma outra experiência bem-sucedida, embora restrita à comunidade acadêmica, é o portal $\mathrm{arXiv}^{3}$, originalmente desenvolvido em 1991 no Laboratório Nacional de Los Alamos como um arquivo virtual para preprints na área de física. Posteriormente foi expandido de modo a incluir áreas correlatas tais como matemática, ciências não-lineares, ciências da computação, biologia quantitativa e estatística, além de suas mais diversas subáreas. Atualmente é armazenado e operado pela Universidade de Cornell, com espelhos por todo o mundo ${ }^{4}$. Embora o arXiv seja um domínio aberto para publicações sem a revisão de artigos por pares, desde 2004 as publicações são submetidas a um grupo de editores que se revezam na tarefa de assegurar uma qualidade mínima aos conteúdos armazenados. Os artigos aceitos pelo arXiv compõem 
hoje mais de meio milhão de preprints, ao passo que os acessos ao portal contabilizam picos mensais de até um milhão de visitas. Embora a maioria dos textos postados no arXiv acabe sendo publicado em periódicos com processo convencional de análise por pares, há casos de autores que não se preocupam em fazê-lo. O caso mas emblemático é o do matemático russo Grigori Perelman, que publicou no arXiv em 2003 a demonstração da conjectura de Poincaré ${ }^{5}$, uma das mais importantes demonstrações matemáticas das últimas décadas, que o levou a ganhar (e recusar) a medalha Fields em 2006.

O problema colocado pela possibilidade de publicação científica de amplo acesso sem filtros de arbitragem é novamente relacionado à atribuição de mecanismos de confiabilidade da informação. Vários mecanismos têm sido propostos, por exemplo: a revista digital aberta $E$-conomics ${ }^{6}$ permite a publicação de artigos de discussão após aprovação de editores associados encarregados apenas de verificações formais. Durante um período de oito semanas tanto árbitros quanto leitores registrados podem publicar comentários públicos sobre artigos submetidos. Após a rodada de comentários, editores tomam decisões de publicação ou rejeição, contudo, todos os artigos continuam disponíveis para a comunidade. O processo de publicaçãoé mais rápido e mais democrático do que o das revistas tradicionais. Boas idéias menos ortodoxas correm menor risco de acabarem ignoradas por razões diferentes de seu mérito acadêmico.

Novamente, a dinâmica parece adquirir contornos evolucionários: novas idéias seriam publicadas com pouco controle e um processo descentralizado de recombinação e seleção se encarregaria da definição de quais delas seriam aceitas e quais rejeitadas. A questão aqui é se tal processo descentralizado tenderia a submergir em um oceano de trabalhos irrelevantes ou faria emergir espontaneamente e de forma dominante idéias importantes. Talvez a complexidade, variedade, beleza e eficiência que observamos no mundo biológico contenha a resposta que procuramos.

\section{AS BIBLIOTECAS DE BABEL}

Estima-se $^{7}$ que haja atualmente cerca de 60 bilhões de documentos espalhados por todo o mundo e disponíveis para consulta na www. Leitores de qualquer parte do planeta, munidos de tecnologias agora comuns, podem consultar os catálogos da Biblioteca do Congresso Americano em Washington, das Bibliotecas Nacionais de Paris ou de Madri, ou das bibliotecas da Universidade de São Paulo.

A disponibilização dos próprios acervos aos usuários por meio de downloads completos já é uma possibilidade real. O Projeto Gutenberg ${ }^{8}$, por exemplo, foi o primeiro domínio a disponibilizar os chamados $e$-books na internet. O projeto e seus associados disponibilizam gratuitamente no momento cerca de 100 mil volumes eletrônicos. Nele é possível encontrar livros nos mais diversos idiomas: inglês, francês, espanhol, alemão, chinês e latim, entre outros. Encontram-se ali de importantes obras em língua portuguesa, como os Os Lusíadas ou A Cidade e as Serras, a Mark Twain, J. Arthur Thompson, Charles Dickens e William Shakespeare.

Em um projeto ainda mais amplo, o Internet Archive ${ }^{9}$, ambiciona-se a digitalização e disponibilização gratuita de todos os acervos mundiais não só de livros, mas também de vídeos, sons e versões históricas de sítios na internet. O acervo atual, com cópias em São Francisco, Alexandria e Amsterdã, já conta com mais de um milhão de volumes e cerca de 500 mil arquivos de áudio e vídeo.

A introdução de novas tecnologias produz reconfigurações na capacidade produtiva das sociedades humanas; em particular, a introdução de técnicas capazes de reduzir abruptamente os custos de reprodução de material escrito levou a expansões igualmente descontínuas na quantidade de informação gerada e disponibilizada. Como padrão, essas transições tecnológicas produzem, num primeiro momento, grande resistência, seguida de um período de acomodação e reorganização da forma
5 Em: http://arxiv.org/abs/ math.DG/0303109 e http://arxiv.org/abs/math. DG/ 0307245.

6 Em:http://www.economicsejournal.org.

7 Em: http://www.worldwidewebsize.com.

8 Em: http://www.gutenberg. org/wiki/Main_Page.

9 Em:http://www.archive.org. Uma interessante apresentação do criador do projeto Brewster Kahle, pode ser acessada em: http://www. ted.com/index.php/talks/ brewster_kahle_builds_a_ free_digital_library.html. 
como a informação é recebida, gerenciada e produzida.

Na Europa do século XII uma Bíblia de pergaminho poderia ser vendida pelo equivalente moderno a centenas de milhares de reais, demandaria peles de cerca de 300 carneiros e o trabalho de um ano de um copista especializado (Durant, 1950, pp. 810). A introdução do papel tornou a produção de livros mais acessível e barata e trouxe a preocupação de que isso incentivaria pessoas a preencherem páginas de escritos sem valor (Burke, 1999, pp. 21). Quando a imprensa foi introduzida por Gutemberg no século XV, a mesma preocupação com o excesso de produção e ausência de conteúdo repetir-se-ia. Ao saber da possibilidade de comunicação praticamente instantânea entre o Maine e o Texas, Henry Thoureau teria perguntado: "But what do they have to say to each other?" (Burke, 1999, pp. 21). A introdução da televisão provocou preocupação com uma progressiva redução no nível intelectual da população.

Nossa visão privilegiada a posteriori nos permite, no entanto, vislumbrar um progressivo processo de aumento em nossa capacidade de armazenamento de informação, da escrita às memórias em estado sólido, em nossa capacidade de transmitila, do papel à web, e em nossa capacidade de acessá-la, da imprensa às redes sem fio. Como conseqüência geral, também assistimos à aceleração da produção de informação por um processo de reprodução, mutação e recombinação.

Os problemas causados pela sobrecarga de informação também foram imaginados por Borges (2000, pp. 94):

“Otros, [...], creyeron que lo primordial era eliminar las obras inútiles. Invadían los hexágonos, exhibían credenciales no siempre falsas, hojeaban con fastidio un volumen y condenabam anaqueles enteros: a su furor higiénico, ascético, se debe la insensata perdicíon de millones de libros. [...] pero quienes deploran los 'tesoros'que sufrenesi destruyó, negligen dos hechos notorios. Uno: la Biblioteca es tan enorme que toda reducción de origen humano resulta infinitesimal. Otro: cada ejemplar es único, irremplazable, pero (como la Biblioteca es total) hay siempre varios centenares de miles de facsímiles imperfectos: de obras que no difieren sino por una letra o por una coma".

Central à questão é o fato de que nossas limitações cognitivas e de tempo requerem que sejamos capazes de reconhecimento prévio da relevância da informação. Como resposta às seguidas expansões na geração de informação há, portanto, a necessidade de classificação e filtragem. A classificação do conhecimento nos moldes das enciclopédias alfabeticamente indexadas ou números PACS ${ }^{10}$ sendo expressões dessa necessidade de filtragem de informação.

Novas possibilidades de filtragem surgem com o advento das ferramentas de busca. Digitalizado o conteúdo de uma biblioteca, segue-se o processo de indexação, que consiste da coleta de palavras-chave em um texto, processo efetuado manualmente em bibliotecas convencionais. O acervo gigantesco da www torna necessária, noentanto, a utilização de técnicas de indexação automatizadas. No processo de indexação, a cada texto atribui-se um vetor de representação na forma de palavras-chave com pesos definidos pela frequiência de cada termo. Para utilização na busca criam-se tabelas invertidas nas quais um dicionário de termos é ligado aos documentos que os contêm com as respectivas informações sobre a freqüência de cada termo em cada texto. A relevância de cada texto irá, assim, depender diretamente da coincidência entre a combinação lógica empregada na busca (query) e a incidência dos termos no texto, considerada sua freqüência.

Do ponto de vista da filtragem de informação, a questão de relevância de um texto é essencial. O hipertexto possibilita a implementação de um sistema automatizado de avaliação dessa relevância sem necessidade, ao menos em primeira aproximação, de uma inviável avaliação manual do significado dos textos. Em 1998, Sergey Brin e Lawrence Page, criadores do Google, propuseram o PageRank (Austin, 
2008). Esse algoritmo de ordenação por relevância utiliza os links em hipertexto a partir de princípios simples: cada link é entendido como um voto de um texto em outro, votos de um texto recebendo pesos proporcionais a sua relevância. Posto dessa maneira a impressãoé de um raciocínio circular: a definição de relevância de um texto depende da própria definição de relevância. A idéia aqui é resolvida pela atribuição de uma estrutura algébrica com uma matriz a especificar o processo de atribuição de relevâncias a partir das próprias relevâncias. Técnicas computacionais intensivas para solução de problemas algébricos dessa natureza são bem conhecidas, mesmo para casos envolvendo dezenas de bilhões de documentos (Berry \& Browne, 2005).

Novas tecnologias de expansão da www prometem tornar ainda mais sofisticada a conexão entre textos e a sua avaliação de relevância. A web semântica (BernersLee et al., 2001) consiste da introdução de informação de significado aos textos digitalizados da www. Essa informação seria utilizada por agentes de software para criação de metalinks entre textos, possibilitando a descoberta de conexões para além da simples coincidência de termos ou da presença de hiperlinks. Com a web semântica seria possível, por exemplo, requisitar ao agente que navegue na rede complexa de conhecimento em busca de informação com significado relacionado a nosso tema de interesse. Teríamos assim uma ferramenta de software voltada literalmente à produção de pontes interdisciplinares.

As conseqüências da utilização de ferramentas de busca como filtros de informação são profundas. Um filtro convencional utiliza classificações de assuntos ou palavras-chave predefinidas. A geometria do conhecimento muda, nesse caso, de forma lenta e tende a respeitar critérios de pertinência mais rígidos. Esses critérios de pertinência aparecem com a necessidade da instalação física dos volumes em uma biblioteca convencional. Assim, um volume que satisfaça um número de condições de pertinência para ser classificado como na área de física será assim classificado e alocado na vizinhança de outros volumes que satisfaçam os mesmos critérios. Ao contrário, numa biblioteca digital, munida de filtros de busca, o estabelecimento de critérios de pertinência perde o sentido, visto que é possível navegar pela rede complexa de conhecimento utilizando como guias palavras-chave (ou idéias, no caso da web semântica) e indicadores de relevância. As divisões de localização física deixam de ser necessárias e a vizinhança de conjuntos de pertinência é substituída por links de significados na rede complexa.

As classificações em áreas de conhecimento têm o papel inicial de filtro de informação mas acabam recebendo valor ontológico. Repetindo-se o mesmo processo para os novos filtros de informação na forma de ferramentas de busca, podemos esperar mudanças ainda mais profundas na forma como a própria pesquisa científica é realizada. A idéia de interdisciplinaridade faz sentido se a geometria do conhecimento permite a identificação de fronteiras bem definidas para disciplinas. Na figura da página seguinte vemos uma rede que representa relações entre temas de pesquisa. A rede foi construída a partir de palavras-chave de 800 mil artigos registrados na base de dados de publicações Web of Knowledge ${ }^{11}$. Cada círculo simboliza artigos que contenham as palavras-chave representadas como flagelos na figura, o tamanho desses círculos relaciona-se ao número de artigos compartilhando as mesmas palavras-chave. Dois círculos são interligados quando há intersecções nos conjuntos de palavraschave. Círculos são tão mais próximos na representação bidimensional quanto maior o número de interligações. Nota-se que a rede complexa é conexa, nenhum grupo de artigos em isolamento total. Cada região é rotulada como uma área de conhecimento. Nessa representação, no entanto, esses rótulos acabam por representar apenas convenções, visto que não há fronteiras claramente identificáveis. Ao utilizarmos ferramentas de busca caminhamos através dessa rede sem a necessidade de recorrer às classificações disciplinares usuais ou à classificação alfabética de verbetes enciclopédicos.
I I Em: http://www.isiwebofk nowledge.com. 
Research and node layout by Kevin

Boyack and Dick Klavans; data from

Thompson ISl; graphics \& typography by W. Bradford Paley. Commissioned and partially supported by Katy Borner and the Places and Spaces: Mapping Science exhibition. Copyright (c) 2006 W. Bradford Paley, all rights reserved

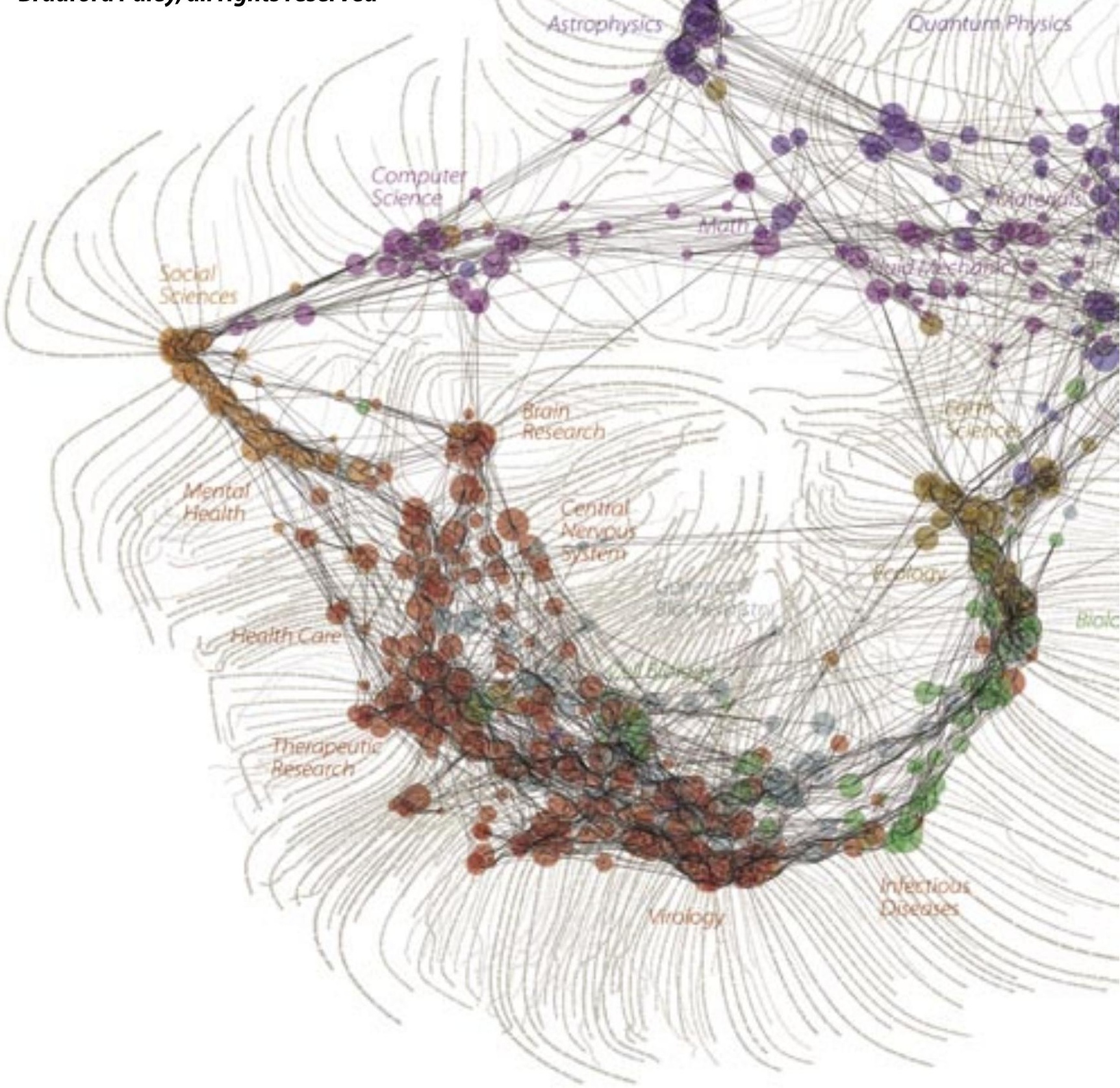




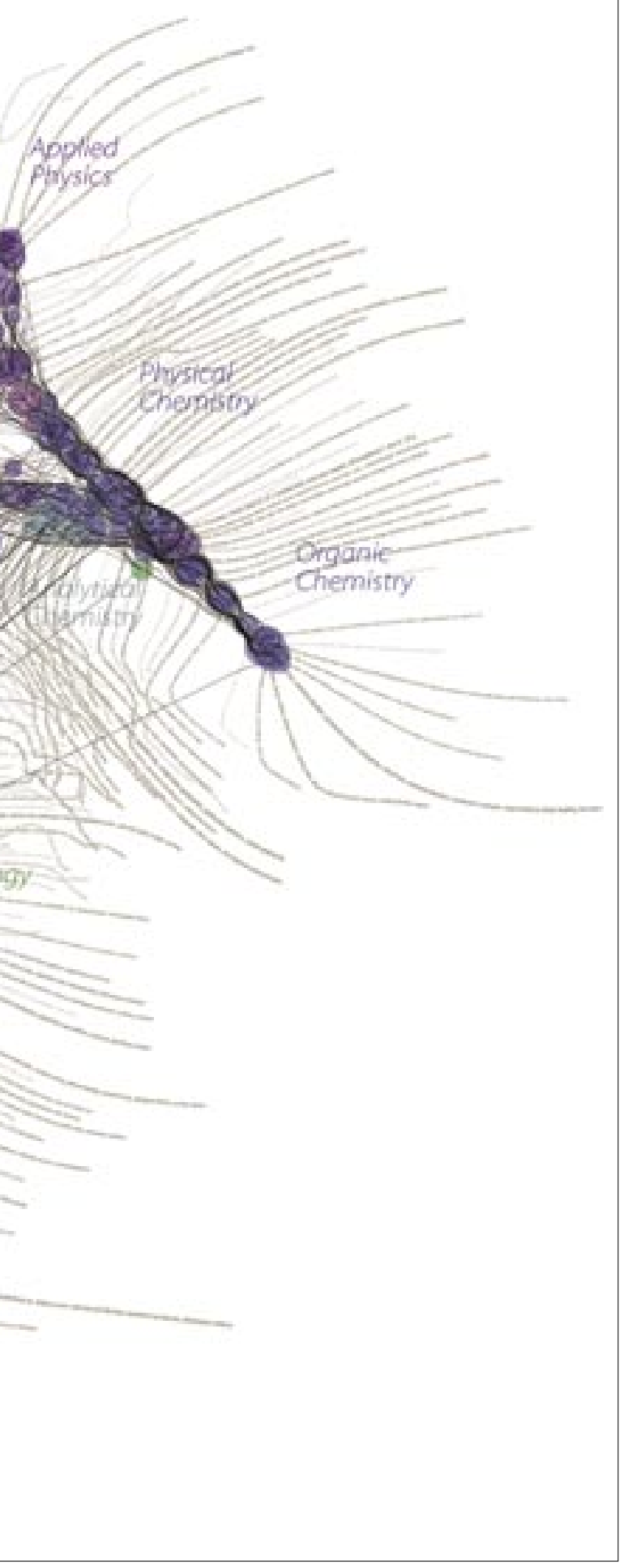

Uma conseqüência importante do processo é a diluição completa de fronteiras disciplinares. Assim passa a fazer sentido atuar em uma região da rede identificada convencionalmente como, por exemplo, "Ecologia", no entanto, perde o sentido a afirmação de que tais e tais tópicos estejam dentro ou fora de uma dada disciplina. A própria noção de interdisciplinaridade se enfraquece, sendo substituída pela de excursão, tendo as tecnologias de busca como veículo, pela rede complexa de conhecimento.

\section{A LEITURA DO HIPERTEXTO}

A possibilidade de produção de leitores de livros eletrônicos tem sido explorada desde o fim da década de 90, quando foram lançados o rocketbook e o readerbook, duas idéias que naufragaram devido à pequena oferta de títulos e a uma interface considerada pouco agradável pelos leitores. Alguns modelos posteriores, como o softbook, prometiam até mesmo capas de couro e cheiro de livro novo na tentativa de recuperar parcialmente a experiência do livro tradicional.

Mais recentemente foi lançado o leitor de livros eletrônicos Kindle. A um custo acessível, o Kindle permite armazenar centenas de livros e selecionar um catálogo de milhares de títulos disponíveis para compra on-line. Com acesso sem fio à rede, o aparelho vai além de um livro eletrônico, também permitindo ao usuário acesso a jornais, revistas e blogs. Tecnologias como fax, telefonia celular e livros eletrônicos dependem da existência de redes com conectividade, apresentando retornos crescentes de escala. Assim, é possível que os leitores eletrônicos encontrem agora condições de absorção mais favoráveis do que aquelas encontradas no final da década de 90.

A mídia eletrônica não é apenas uma forma diferente de apresentação para o livro tradicional, a estrutura fluida do hipertexto pode permitir a introdução de dinâmicas de leitura muito distintas da experiência 
seqüencial convencional. Mesmo antes da introdução dessas novas possibilidades tecnológicas, a literatura já vinha realizando experiências nessa direção.

O caso de Georges Perec é exemplar. O escritor francês imaginou sua obra mais importante - La Vie Mode d'Emploi - Romans (1978) - a partir da convivência de dois modos de leitura: a convencional e a não-seqüencial. O leitor pode começar a ler o texto seguindo a ordem dos capítulos proposta pela organização material do livro ou a partir do sumário que, além da marca de ordem convencional, produz “links" entre capítulos referentes ao mesmo personagem ou ao mesmo espaço do imóvel (elevadores, escadas - o romance narra a vida das personagens no prédio de apartamentos da rua fictícia Simon-Crubellier em Paris) através de uma numeração arábica ao lado dos títulos dos capítulos. Assim, sem obedecer à sequiência dos capítulos do livro, o leitor pode seguir apenas a história de Percival Bartlebooth (um dos personagens principais do livro) pulando da página 148 da edição francesa para a 397, 454, 495 e, finalmente, 574 .

Essa característica não-seqüencial encontra-se radicalizada na chamada literatura hipertextual, que supõe a construção de poemas e narrativas com a presença de hiperlinks remetendo a outros contextos, indefinidamente, numa materialização da noção de "obra aberta". Ora, é exatamente essa característica da literatura hipertextual que tem sido colocada em perspectiva por uma série de críticos literários quando afirmam que a ausência de um desenrolar temporal da trama textual e de uma conclusão fechada e tradicional impede a organização hierárquica dos eventos apresentados, condição necessária para a construção de sentido durante a leitura. O resultado é uma construção textual fraca de valor semiótico e que parece favorecer uma significação literal em detrimento de outros níveis de significação textual. O papel do leitor que, num primeiro olhar, parecia expandir-se (uma vez que é o próprio caminho escolhido pelo leitor em sua navegação pelos links que concretiza de forma inédita uma das inú- meras potencialidades da estrutura textual eletrônica, fazendo com que esse seja uma espécie de leitor-autor), pode contrair-se significativamente. Assim, para que a literatura hipertextual se imponha como forma narrativa, ela deve "ultrapassar a etapa [...] do simples dispositivo" e desenvolver novas formas de trabalho com a narratividade (Gervais \& Xanthos, 2008, p.10).

Qualquer que seja o caminho a ser trilhado na conquista dessas novas formas, vale lembrar de como os escritores de várias épocas trabalharam problemas semelhantes. Retornando, mais uma vez, a Georges Perec, vê-se que, em muitos de seus textos (A Viagem de Inverno e A Vida Modo de Usar, por exemplo), o escritor utiliza certas convenções dos romances policiais de forma inédita. Entre outros fatores, Perec opera uma desestabilização da função do "desfecho" narrativo, mantendo a ilusão de fechamento narrativo ao mesmo tempo em que adensa o(s) mistério(s) ao invés de resolvê-lo(s) ${ }^{12}$. Essa desestabilização se faz possível porque Perec desacopla o desenrolar dramático da trama (o que acontece aos personagens) e a apresentação da "verdade" no desfecho da narrativa, mostrando que, na maioria das vezes, é a tensão resultante da convivência de elementos mutuamente exclusivos que faz emergir as melhores soluções literárias.

\section{A TEIA DO CONHECIMENTO}

Tal como Perec, James Burke, autor da premiada série Connections da $\mathrm{BBC}$, faz experiências com narrativas não-sequienciais em seus livros The Web of Knowledge e Twin Tracks. Burke propõe que a forma mais adequada de descrição do conhecimento humano, tanto do ponto de vista histórico quanto em uma biblioteca, seja na forma de teia. No centro teríamos as idéias primordiais, a língua falada, o fogo e as ferramentas de pedra lascada. Essas idéias se recombinariam em novas idéias rumando para a superfície totalmente conectada e em constante expansão, que 
representaria nossas idéias mais recentes. As tecnologias de informação finalmente nos libertariam "de um período da história no qual o cérebro humano estaria limitado pela tecnologia a operar de forma menos do que ótima, visto que o cérebro parece projetado para funcionar melhor da maneira linear e discreta promovida pelo reducionismo" (Burke, 1999, pp. 16).
A possibilidade de publicação irrestrita permitiria explosões cambrianas de idéias que, vencido o desafio de selecioná-las, tornaria mais rica e variada nossa concepção do mundo. Nossas excursões por hiperlinks digitais com auxílio de ferramentas de busca nos permitiriam uma visão mais completa e fidedigna de um mundo totalmente interdependente.

\section{BIBLIOGRAFIA}

AUSTIN, David. Google Finds Your Needle in the Web's Haystack. AMS Monthly Essays on Mathematical

Topics, 2008. Acessível em: http://www.ams.org/featurecolumn/archive/pagerank.html. BERNERS-LEE,Tim; HENDLER, James e LASSILA, Ora."The Semantic Web", in Scientific American,

May/2001.

BERRY, Michael; BROWNE, Murrey. Understanding Search Engines: Mathematical Modeling and

Text Retrieval. Second Edition. Philadelphia, SIAM, 2005.

BORGES, Jorge Luis. Ficciones. Madrid, Alianza Editorial, 2000.

BURKE, James. The Knowledge Web. Nova York, Simon \& Schuster, 1999.

.Twin Tracks. Nova York, Simon \& Schuster, 2003.

CHARTIER, Roger."Do Códice ao Monitor: a Trajetória do Escrito", in Estudos Avançados, 8(21), 1994.

DURANT, Will. A História da Civilização vol. IV, A Idade da Fé. Rio de Janeiro, Record, 1950.

GILES, Jim. "Internet Encyclopaedias go Head to Head", in Nature 438,2005, pp.900-1.

GERVAIS, Bertrand; XANTHOS, Nicholas. Hypertexte, Une Lecture Sans Fin. Acesso em 16 de novembro

de 2008 no sítio http://www.uottawa.ca/ academic/arts/astrolabe/articles/art0036.htm\#1). MANGUEL, Alberto. Uma História da Leitura. São Paulo, Companhia das Letras, 1997.

PEREC, Georges. La Vie Mode d'Emploi - Romans. Paris, Hachette. 1978. 